\title{
Interactive Design as a Model of Creative Communication: the WATT Mobile App in the "Sensitive City" System
}

\author{
Elena Zaeva-Burdonskaya ${ }^{1}$ and Elmira Khusanbaeva ${ }^{1}$ \\ ${ }^{1}$ Moscow State Stroganov Academy of Design and Applied Arts, 9, Volokolamskoe highway, Moscow, 125080, \\ Russia
}

\begin{abstract}
The Smart City program has become a step towards the development of digital space in the urban environment of megacities such as Moscow. Despite the global nature of the idea of the communicative-digital urban model, an attempt at a human-oriented approach remains. In the digital space, the function of anthropocentrism is assumed by interactive design that serves as an adaptation of the manifold urban environment. Design becomes a tool creating a person's comfort zone, implementing various urban socio-cultural scenarios interactively, taking into account the psycho-emotional state of a person.

In the developed concept of WATT interactive application a person acts as an energetic and emotional "component" of the city. The product answers the goal of the design system of the sensual stratum of the environment, forming the concept of a Sensitive city and its important parameter: an indicator mood of the urban environment's mood. The innovative character of the approach lies on the city aimed at the creation of an new energetical product - a tool that forms the eco-energy exchange between the resident and the city, results as an index of resident's "happiness".

The application becomes an example of the hybrid existence of urban environment, harmonizes the relationship between the digital field and the citizen: it supports the emotional and psychological state and offers various rehabilitation programs. This becomes especially relevant due to the need to neutralize the consequences of self-isolation after the pandemic.
\end{abstract}

\section{Keywords}

Interactive design, smart city, anti-globalism, digital technologies, multimedia design.

\section{Introduction}

In the modern digital world stable structures have been formed that combine the number of social processes into global models - often excluding people. An example of such a communicative-digital model is the "smart city" which is implemented in the space of megacities and large cities. The Smart City paradigm arises at the "confluence of two megatrends - urbanization and the digital revolution", and its operational history starts in 2008 when IBM introduced the concept of Smarter Planet with the Smarter Cities initiative [1].

\subsection{The concept of Smart City and the trends of globalism}

The Smart City model is quite multi-vector and variable, and opens up broad prospects for improving various project areas including design. The project tasks of the megalopolis include the improving of an interaction between the citizen and urban infrastructure based on the capabilities of digital graphics. The world-wide urban planning concept ranges from the simplest level to the global level in terms of the depth of the tasks to be solved. It integrates a variety of information and communication

GraphiCon 2021: 31st International Conference on Computer Graphics and Vision, September 27-30, 2021, Nizhny Novgorod, Russia EMAIL: lenartt@gmail.com (E.Zaeva-Burdonskaya); ella14@bk.ru (E. Khusanbaeva) ORCID: 0000-0002-5355-8565 (E. Zaeva-Burdonskaya); 0000-0002-2636-7180 (E. Khusanbaeva)

$\begin{array}{ll}\text { (c) (i) } & \text { (c) } 2021 \text { Copyright for this paper by its authors. } \\ \text { Use permitted under Creative Commons License Attribution } 4.0 \text { International (CC BY 4.0). } \\ \text { CEUR Workshop Proceedings (CEUR-WS.org) }\end{array}$ 
technologies such as public services, education, urban transport, energy consumption, health, ecology, etc. In 2014 the Government of Singapore launched the Smart Nation project which brings together government officials, entrepreneurs and scientists with a digital vision of the economy, government, and society [2]. The creation of the "World Smart City" award became an incentive to digital globalism.

For all the global nature of the idea, the purely digital model still attempts a humanitarian-oriented approach. The British Standard Institution (BSI) describes a smart city as "the effective integration of physical, digital, and human systems in an artificially created environment to ensure a sustainable, prosperous, and inclusive future for citizens"[3]. Among the components of the smart city concept, along with the parameters of good manageability, accessibility and openness to people, based on integrated services and infrastructure, etc. [4] the most important is human-centricity: the city is focused on residents, businesses, employees and tourists. However, the design process in the "smart city" system tries to exclude human participation from the decision-making process as much as possible. The priority is increasingly given to technology, not to the person.

"...Crucial planning phases... tend to reduce community involvement. In fact, they would rather adopt basic technologies and generic master plans, than questioning the problems faced by citizens and generating a solution-based design... John Harlow, a smart city research specialist at The Emerson College Engagement Lab, even states that "Smartness in cities comes from people understanding what's important to them and what problems they are experiencing". Therefore, a city cannot be considered smart if it doesn't revolve around humans." [5].

The domestic strategy of the "smart city" is focused primarily on the rational management of the city, on improving its efficiency, security and economic growth [6]. However, the issue of the impact of multi-layer digital infrastructure on the psycho-emotional state of citizens remains without attention. Against this background, the example of "Intelligent Lighting" is the most emotionally capacious aspect of the implementation of the smart city concept. "In the Smart City Standard developed by the Ministry of Construction of Russia in October 2018, among the criteria for classifying cities in the category of "smart", the modernization of urban and indoor lighting is indicated... The first and largest domestic development with a large-scale application of digital content of Smart City technologies was the project "Luminous City" (Ivanovo)" [7].

Multi-layer digital infrastructures (wireless Internet access, mobile networks, the Internet of things) provide the city with continuous dynamics and change, modify the processes of its metabolism, adding an additional stratum to the urban structure - an interactive one. Design as a form of a creative activity becomes a tool for forming a person's comfort zone, regulating the degree of his interaction with the environment. With its help the adaptability of urban space appears. By implementing various urban socio-cultural scenarios in projects, it becomes possible to take into account the psycho-emotional state of a person.

\subsection{Problematic situation}

The article raises the problem of developing and creating a model of a sensory-interactive environment of human-city interaction using design and multimedia technologies - with mobile application as an example. Within its framework a number of issues were raised, the solution of which has to improve the psychological state of the inhabitants of the megalopolis, to update the design potential of the modern urban environment. Among them is the search for interactive mechanisms of dialogue between a person and a city based on psycho-emotional sensory content.

\section{Method}

The proposed concept of a" Sensitive " city creates an urban environment that is sensitive ("sensitive" - lat. Sensitivus) to the needs of the inhabitants of the metropolis and adapted to the emerging problems. In the continuous search for the goodness for a person, negative factors are eliminated.

The Sensitive City [8] has the characteristics of a smart and happy city at the same time, and includes a holistic program for harmonizing the psychological state of the resident in his sensitive layer. For this purpose, a sensory-interactive environment of interaction between a person and the city was developed 
on the example of the Moscow metropolis, using the means of multimedia design. The project model of the WATT mobile application combines the ideology of a citizen and a layer of media design technologies in order to create a personal program of psychological rehabilitation.

The formulation of the design concept and the development of custom scripts for the product required a well-grounded objective opinion of the consumer. A questionnaire was used as a method of sociocultural analysis. The survey was conducted among Muscovites aged 18 and over without restrictions, taking into account the barrier-free environment. The most active respondents included the following groups: young people and families with school-age children. The survey was compiled on the basis of a questionnaire consisting of 40 questions. Among them, the most significant for the study was the section devoted to the resident's personal perception of urban space. In the answers, the importance of emotional comfort of a person in an urbanized environment was voiced. The results of the survey showed that the level of material well-being is an important but not a decisive factor affecting the happiness of a citizen. Environmental problems, the level of security and a sense of change for the better in one's hometown came to the fore. The results of the study were supplemented with data from a social survey of Muscovites conducted earlier in 2018. The topic was: do they consider their city convenient for living, what problems it has, etc., and the conclusion was: "Moscow is a friendly city".

The WATT mobile app has the functions of fixing the emotional state of a citizen and the urban environment as well as a program for harmonizing the psychological state of a resident of Moscow in a game form (Figure 1). The gadget as an optimal tool for information exchange between the physical and virtual world of urban infrastructure has become the basis for project interaction in a sensitive city [9].

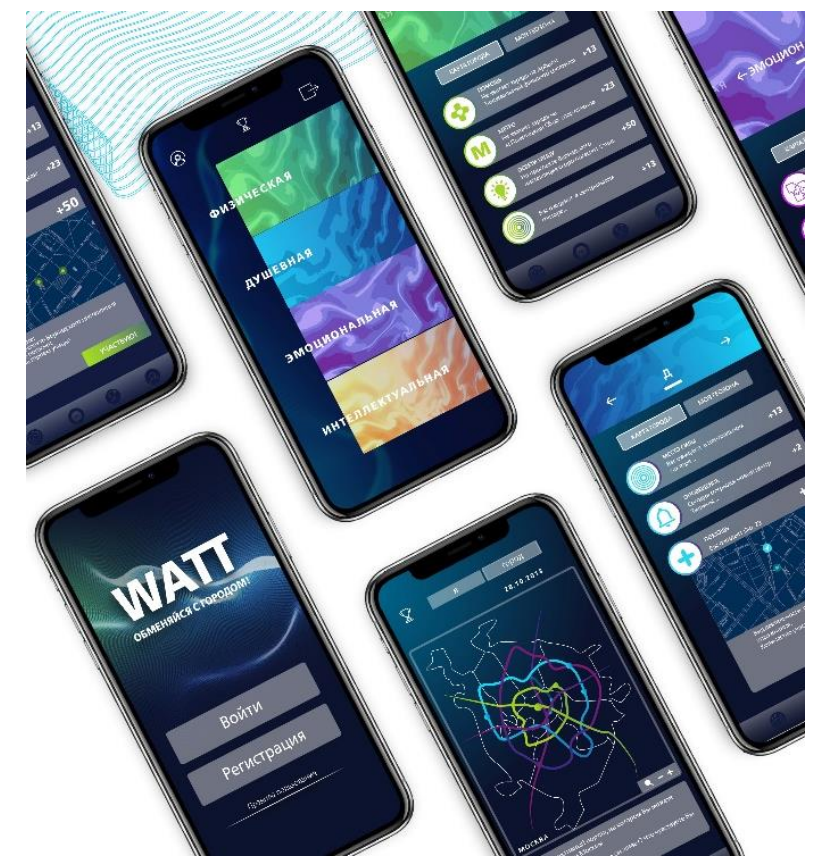

Figure 1: Demo version of the WATT mobile app. Interactive design solution of the "Sensitive City"

Before developing the graphical interface of the application, a navigation model (the connectivity of the application screens) was created and the hierarchy of its components was thought out. The graphic interface of the application was developed in Adobe Photoshop and Adobe Illustrator. The development of the animated user interface of the demo version was carried out using the Principle prototyping tool (Figure 2); the frontend part - with android studio, x-code; the server part - with MySQL. Development of interactive installations - using avr studio technology. 


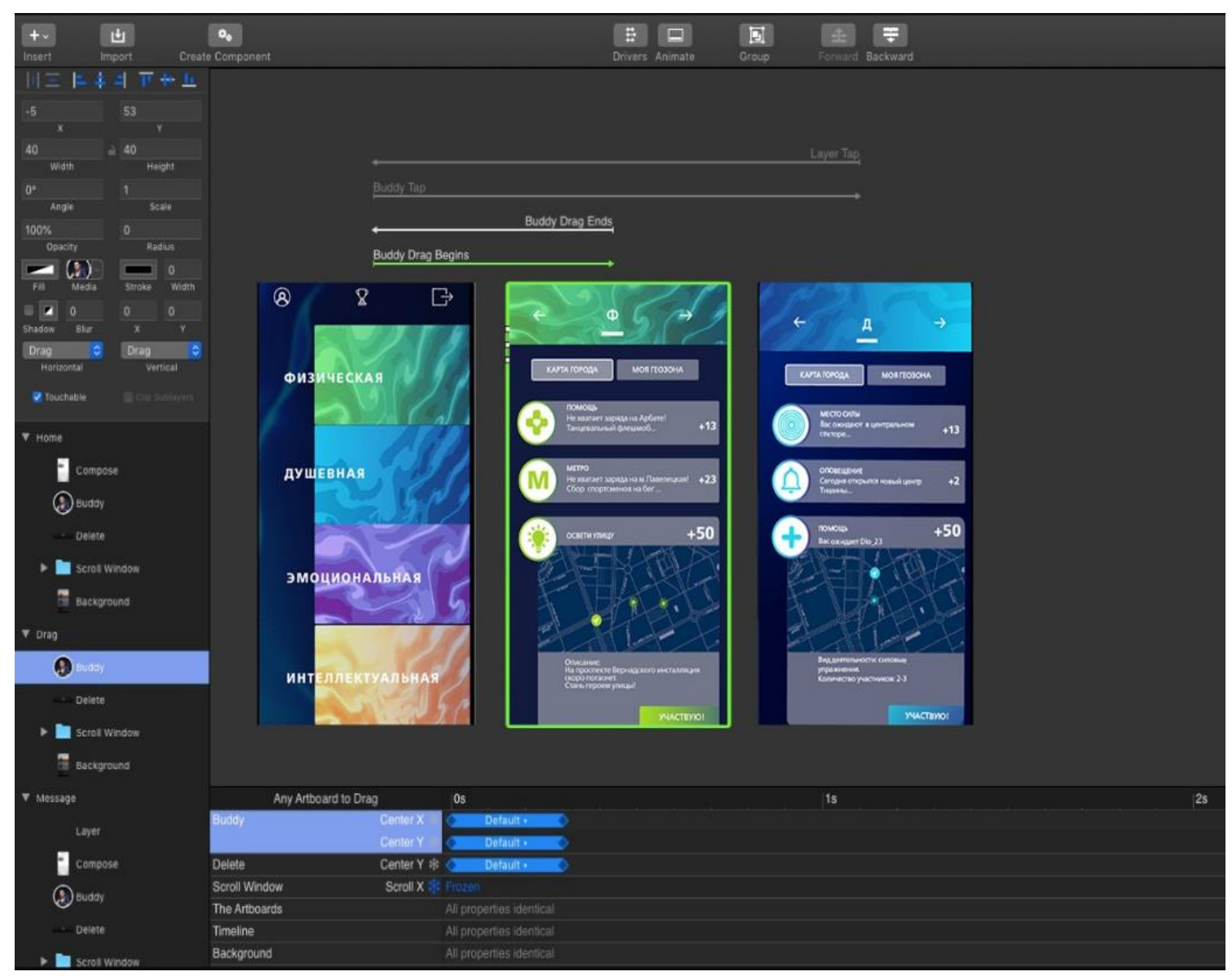

Figure 2: Screenshot: development process of the animated user interface of the WATT application demo version, using the Principle program

\section{The result}

The design concept of the application "People as the energy of the city" reveals the main wealth of any city: a person as its energetic and emotional "component". The energies (emotional, physical, intellectual or mental) of people charge the city, shaping its mood. Man himself becomes the creator of the "sensitive" urban stratum. The concept is based on a study [8] of the characteristics of "smart" and "happy" cities, which made it possible to use the structure of a smart city in the Application. According to its definition, the viability, operability and sustainability of information and communication technologies are based on three parts: collection, transmission of data and their "processing" (analysis) in order to understand what is happening now and what may happen next [10].

According to the proposed scenario, acquaintance with the application takes place during the "Charge the City" festival. After downloading the application from the festival's site to a smartphone the user is invited to become a "city generator". After registering he gets access to the content and the opportunity to take action: the main screen of the application offers a choice of 4 "energy routes" (Figure $3)$. 


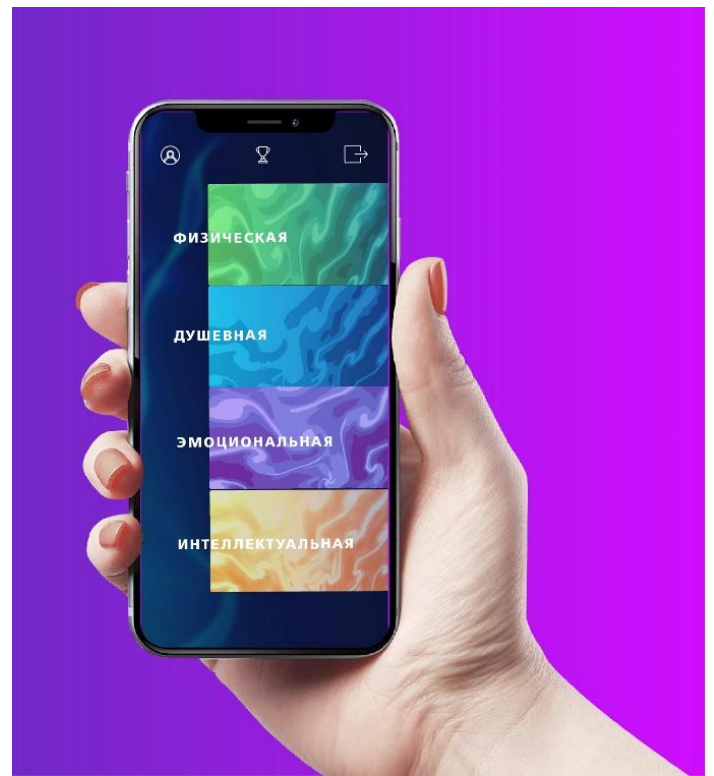

\section{Energy routes}

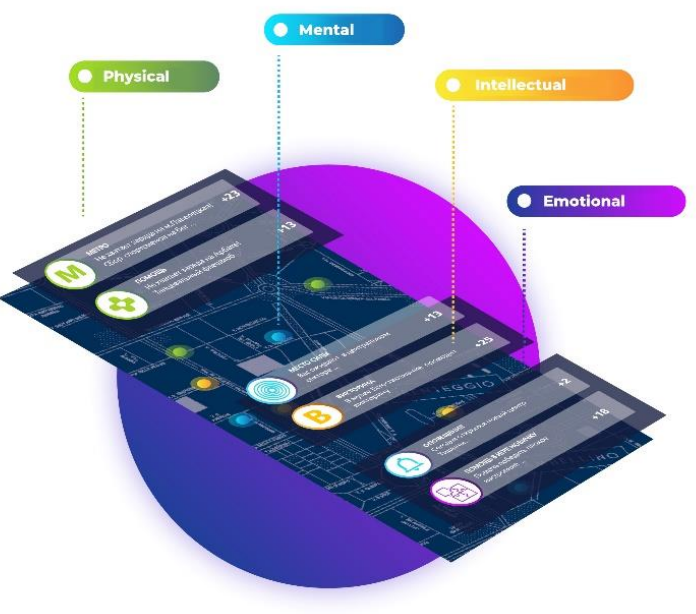

Figure 3: Energy routes in the WATT application

Energy routes are based on the results of the conducted research, and form a system of harmonious interaction of a person with the city. These are: Physical energy (health), Mental energy (comfort), Emotional energy (positive, confidence in the future) and Intellectual energy (learning). For each energy environment, scenarios of energy exchange - routes around the city of Moscow - have been developed. The script programs include tasks for the interested user in different areas (sports, art, culture, charity, etc.). Physical interaction between a person and a city takes place at metro stations, sports stops, activity sites, bike paths, etc., using modern technologies of alternative energy [11]. The emotional exchange is formed by the preventive points of the city, where you can throw out the accumulated psychological energy: interactive game zones and dance flash mobs. Intelligent sharing activities - creative communities and multimedia quizzes. The mental exchange of a person and a city includes places of power, joy of attraction, anxiety, boredom and silence.

The choice of a color scheme for a graphic application is closely related to the theory of the psychology of color perception. The closest one to the figurative color concept is the visual picture of a landscape at sunset, when the colors of nature, familiar during daytime, acquire a mystical shade of purple-lilac bluish-lilac tones. At the same time, this palette is within the bounds of a stable association with "artificial" cold screen colors. The gamut of the graphical interface uses basic (cyan and yelloworange) and composite (violet and green) colors that simultaneously form "color pairs" with each other, being complementary. The color codes of the energy routes are based on the psychological characteristics of perception. The light green code (physical exchange) symbolizes "rebirth and peace of mind, has healing and relaxing properties, extinguishes the negative effects of depressive and negative colors" [12]. The blue-blue code of mental exchange is associated (according to M. Lusher) with the need for satisfaction, calmness, stable positive attachment, kindness and stability, motivating a person to effective activity. The violet code of emotional exchange is associated with creativity, fantasy, mystery, sensitivity and intuition, conducive to inspiration, fills one with energy. The yellow code of intellectual exchange stimulates the work of the brain as well as nervous system and is associated with intelligence, optimism and dynamism, and concentrates attention. The selected color coding system makes a harmonious composition at all levels of the project: starting from screen and projection technologies and up to interactive media installations.

The shaping and style-forming element of the design model is a raster grid with metric and metricrhythmic mode. The curvilinear form of the raster has become at the same time the volume-spatial structure of the graphic model, which allows the construction of $2 \mathrm{~d}$ and $3 \mathrm{~d}$ images and objects. The raster structure simultaneously works as a modular grid for building an application interface of any complexity: from infographic symbols to screen backgrounds.

Unlike the existing applications created within the framework of the Smart City program, this product is characterized by a pronounced productive communication between residents and the city, 
which is determined by the psychoemotional state of the user (the concern of the city for the resident, and the resident for the city as a whole). The WATT Application is a mobile aggregator of urban opportunities with segmentation of tasks in accordance with energy humanitarian scenarios. The mission laid down in the Application is to improve the quality of life of a citizen where the main source of functioning of all processes is human energy. The techniques of personalization, saturation with quantum mechanics, gamification, etc. are conditioned and built into the fast rhythm of a megalopolis. The activities and games presented in the application have significantly expanded the range of familiar socially-oriented urban topics: from acquaintance with multimedia attractors and up to exercises that relieve depression and anxiety in an urbanized space.

Motivational moves for the final product are borrowed from computer games: a point system, leaderboards, level progression and achievement badges [13]. The WATT Application has a clear focus on the gaming and competitive aspect that can activate the user's desire for achievement, recognition. The user has a digital energy "avatar", where merits, potential and available tools are included in his information note (Figure 4). In the app you can find like-minded people (adding friends, forming teams, communicating with people close to your location and interests). A fascinating solution with a WOW effect is the use of augmented reality in receiving city bonuses: a surprise for the user appears on the screen of the energy point. For example, a ticket to Butterflyrium is accompanied by an animated 3D butterfly (Figure 5).

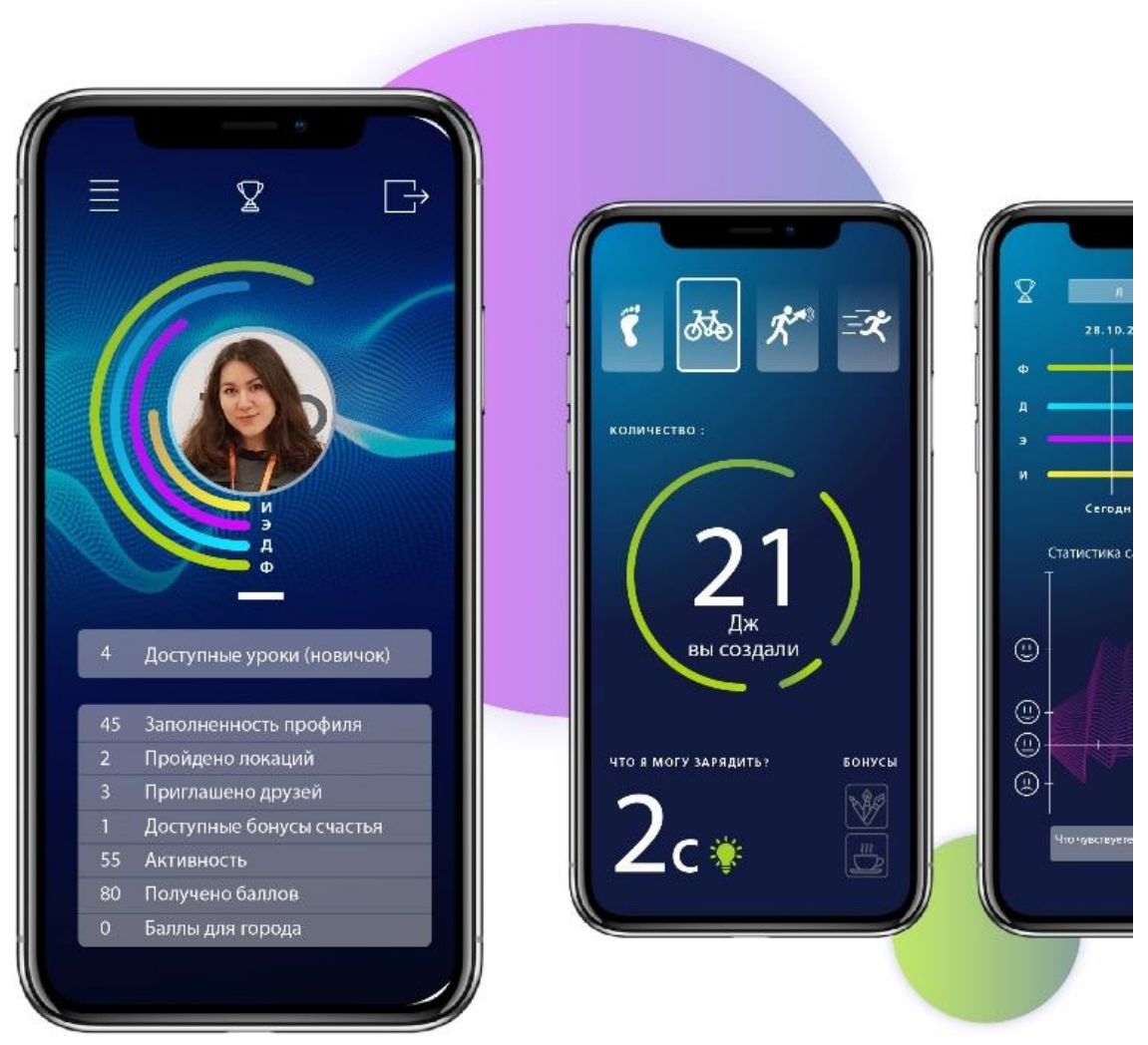

Figure 4: Member profile in WATT Application 


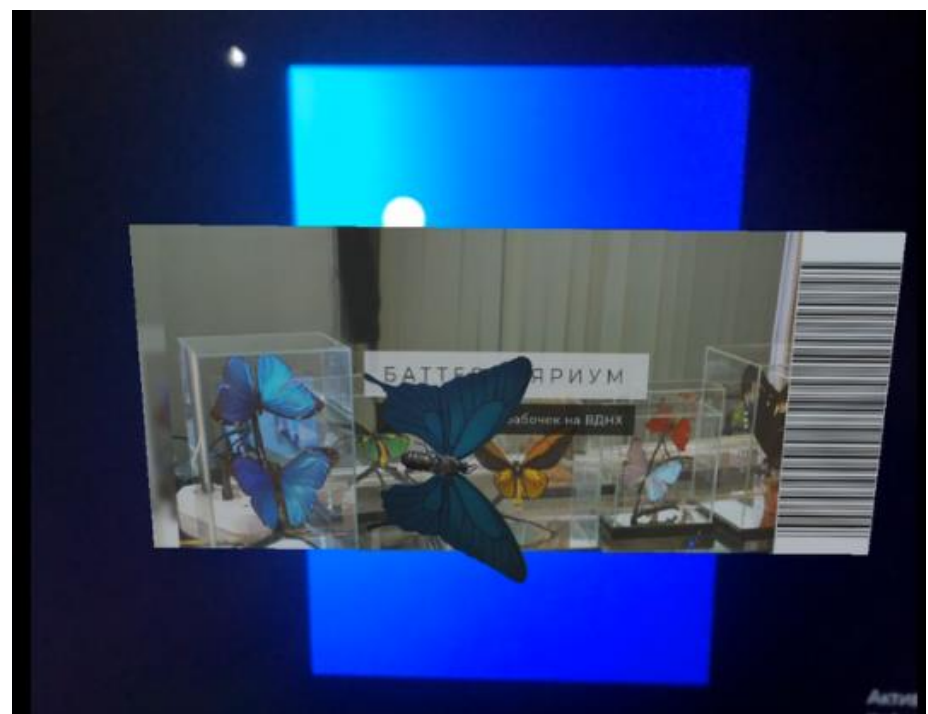

Figure 5: Screenshot from WATT Application

The application is synchronized with the network of thematic city routes and project locations of the "Sensitive City" equipped with interactive equipment. Walking the routes is emotionally stimulating, helps to communicate and organizes the behavior of a citizen in the city. The analysis of the tasks performed in the application and the user's emotional state will allow to determine the mood of the particular district and the city as a whole, forming the most important parameter of the city's environment - the indicator of its mood. The mood and feelings of residents are reflected in the "Heart of the City" (Figure 6). Depending on the prevalence of a particular emotion the indicator lights up with a symbol: color and emoji.

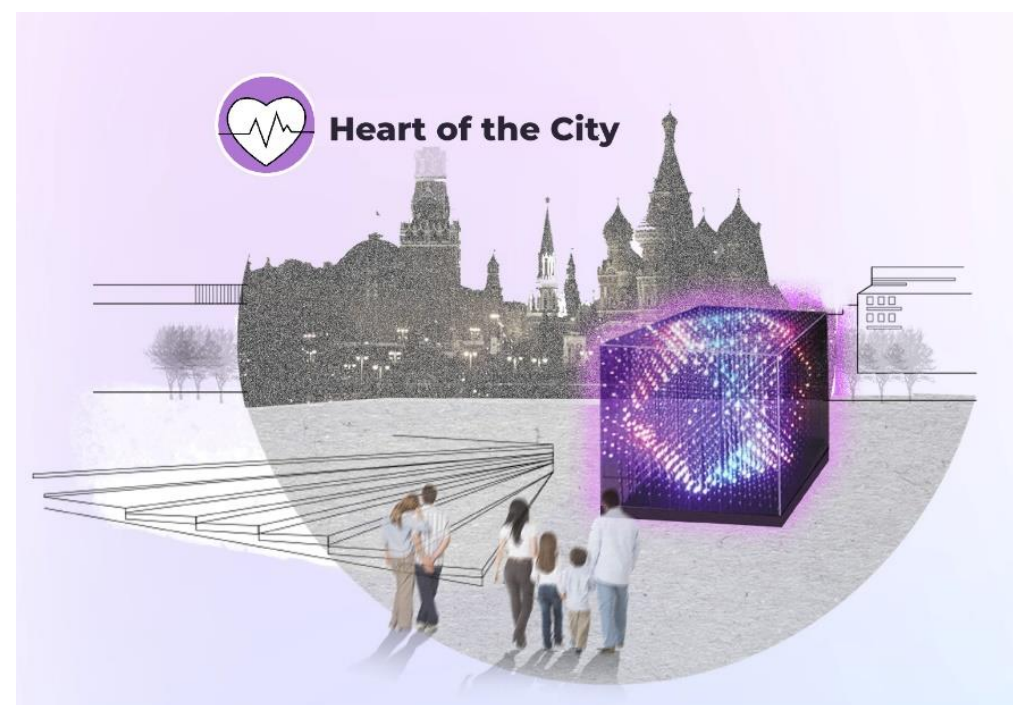

Figure 6: An example of the "Heart of the City" in the design solution for the Sensitive City

The WATT Application system stores data and graphical diagrams about the emotional well-being of the city as well as the user himself. The work of the Application is built on weekly cycles and helps the user to assess his mood, to build city activities according to his feelings. The product combines all five stages of enchantment with the magic of the environment (according to D. Rose's scheme): connectivity, personalization of data, socialization, the presence of a game effect, creation of a story [14].

WATT - An application for a city where a resident can see the emotions of Moscow. How does the city feel? What does a resident feel in this city? A resident forms a map of the city's mood, creates 
emotional ratings of places, opens access to energy routes. He will be able to discover new places in a long-familiar city and create an individual mental map in it.

How can a citizen be happy in the city? The answer to the question is: to become a part of it!

\section{Conclusion}

The first step on the road to anti-globalism could be the choice of a approach to city's "smart" development - unique for each city taking into account its specificity and historical characteristics, in accordance with its priorities and interests. So far, there is no single mechanism for this process where emerging problems change the goals and objectives of a smart city. For example, the aspirations of the concept of such a smart and sustainable city as Dubai is described in three directions: communication, integration and cooperation, based on innovation and agility [15]. The Sensitive City concept continues the search for a humanitarian basis for a smart city of the future, unique for each space.

The WATT mobile App developed within the framework of the concept, together with a functional network of thematic city routes, demonstrates the hybrid existence of the environment. Traditional urban forms can be complemented with an interactive layer. In the created system, a human-centered approach to interface design is important, which will take care of harmonizing the relationship between the digital field and the citizen, maintaining his emotional and psychological state and offering rehabilitation programs. This becomes especially important for leveling the consequences of selfisolation actions during a pandemic.

The innovativeness of the product lies in the orientation of the city not towards consumption but towards the creation of a new energy product: the eco-energetic exchange between the inhabitant and the city. Thanks to their creative basis, the breadth of options for interpreting the activity algorithms proposed in the product will allow everyone to find their own psychological cross-section of interaction with the environment. The WATT Interactive Application solves the design problems of a sensitive layer of the environment that forms the index of "happiness" [16] of a metropolitan resident. It is no coincidence that emotions are included in the discussion layer of specialized scientific conferences such as Smart Cities Week, where "...smart infrastructure is the foundation for future success, for better paying jobs and for a new era of prosperity for all." [17] in the broadest sense of the word.

\section{References}

[1] E. V. Pahomov, Basic model of a smart city, Engineering Bulletin of Don Region 4 (2018). URL: http://ivdon.ru/ru/magazine/archive/n4y2018/5284 (in Russian).

[2] FOBOS Center, Environment: the future of "smart cities", 2018. URL: https://www.meteovesti.ru/news/63665716255-sreda-obitaniya-buduschee-umnymi-gorodami (in Russian).

[3] Tadviser.ru, Smart cities, $2020 . \quad$ URL: https://www.tadviser.ru/index.php/\%D0\%A1\%D1\%82\%D0\%B0\%D1\%82\%D1\%8C\%D1\%8F:\% D0\%A3\%D0\%BC\%D0\%BD\%D1\%8B\%D0\%B5_\%D0\%B3\%D0\%BE\%D1\%80\%D0\%BE\%D0 \%B4\%D0\%B0_(Smart_cities) (in Russian).

[4] Y. Makarova, Smart City: five technologies of the concept, 2020. URL: https://trends.rbc.ru/trends/sharing/5fc625769a79471899ba9ad2 (in Russian).

[5] C. Harrouk, Designing smart cities: A human-centered approach, 2020. URL: https://www.archdaily.com/934186/designing-smart-cities-a-human-centered-approach .

[6] E. V. Semenova, I. Y. Brinkova, Smart city - departmental project of the Ministry of Construction of Russia on digitalization of urban economy, 2021. URL: https://minstroyrf.gov.ru/trades/gorodskaya-sreda/proekt-tsifrovizatsii-gorodskogo-khozyaystvaumnyy-gorod (in Russian).

[7] A. Anikin, Smart City of Ivanovo. An interview with Alexey Anikin, Modern Lighting Technics 6 (2018) 2-6 (in Russian).

[8] E. R. Khusanbaeva, E. A. Zaeva-Burdonskaya, Design in the system of project dialogue between a person and a city (on an example of Moscow), in: "Attempt at writing-2018", Moscow State Stroganov Academy of Design and Applied Arts, Moscow, 2019, pp. $72-77$ (in Russian). 
[9] E. R. Khusanbaeva, A gadget as a tool for the potential development of the "person - city environment" system. Technologies of project interaction, in: Figurative characteristics of the urban environment as a resource for the development of the territory, Materials of the All-Russian scientific-practical conference, Siberian branch of Russian Heritage Institute, Omsk, 2020, pp. 5863. URL: https://biblioclub.ru/index.php?page=book_red\&id=612137 (in Russian).

[10] Smart cities readiness guide, Smart Cities Council, 2015. URL: http://www.estudislocals.cat/wpcontent/uploads/2016/11/SmartCitiesReadinessGuide.pdf.

[11] E. R. Khusanbaeva, E. A. Zaeva-Burdonskaya, World experience in the use of innovative alternative energy technologies in urban space (on an example of Moscow), in: Design and art the strategy of design culture of the XXI century, Materials of the All-Russian scientific-practical conference "DISK-2": Part II, Moscow, 2018, pp. 196-200 (in Russian).

[12] Portal about psychology, The psychology of color and the meaning of colors in psychology, 2017. URL: https://psychologyc.ru/psixologiya-cveta-i-znachenie-cvetov-v-psixologii (in Russian).

[13] J. McGonigal, Reality is broken: why games make us better and how they can change the world, The Penguin Press, New York, NY, 2011.

[14] D. Rose, Enchanted objects: design, human desire, and the internet of things, Scribner, New York, NY, 2014.

[15] N. Dassani, D. Nirwan, G. Hariharan, Dubai - a new paradigm for smart cities. KPMG, 2015, pp. $10-12$.

[16] The Happy Planet Index, 2020. URL: http://happyplanetindex.org.

[17] L. Enbysk, Smart cities week returns to Washington, D.C. Oct. 3-5 with focus on smart infrastructure, Smart Cities Council, 2017. URL: https://www.smartcitiesdive.com/pressrelease/20170831-smart-cities-week-returns-to-washington-dc-oct-3-5-with-focus-on-smart. 